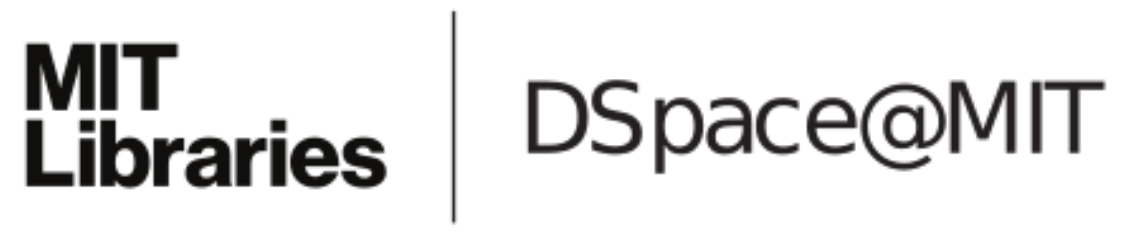

\author{
MIT Open Access Articles
}

Incorporating safety risk in early system architecture trade studies

The MIT Faculty has made this article openly available. Please share how this access benefits you. Your story matters.

Citation: Leveson, Nancy, and Nicholas Dulac. "Incorporating Safety in Early System Architecture Trade Studies." Journal of Spacecraft and Rockets 46.2 (2009): 430-437.

As Published: http://dx.doi.org/10.2514/1.37361

Publisher: American Institute of Aeronautics and Astronautics

Persistent URL: http://hdl.handle.net/1721.1/58929

Version: Author's final manuscript: final author's manuscript post peer review, without publisher's formatting or copy editing

Terms of use: Attribution-Noncommercial-Share Alike 3.0 Unported 


\title{
Incorporating Safety Risk in Early System Architecture Trade Studies
}

\author{
Nicolas Dulac ${ }^{1}$ and Nancy Leveson ${ }^{2}$ \\ Massachusetts Institute of Technology \\ Cambridge, Massachusetts 02139
}

\begin{abstract}
Ideally, safety should be a part of the early decision making used in conceptual system design. However, effectively evaluating safety risk ${ }^{3}$ early enough to inform the early trade studies is not possible with current technology. This paper presents a new approach to preliminary hazard analysis that can be performed prior to system design selection and thus can influence key architectural decisions that will be impossible to change later in the system lifecycle. The approach is illustrated through a concept evaluation and refinement study for the new NASA space exploration.
\end{abstract}

\section{Introduction}

Traditional system engineering activities recognize the need for trade studies early in the architecture concept formation phase [1]. Attempts have been made at evaluating some properties of candidate architectures before a system is implemented. The system properties (and associated evaluation techniques) are very different depending on the application domain, problem formulation, requirements, and system development phase.

\footnotetext{
${ }^{1}$ Nicholas Dulac, Postdoctoral Researcher, Department of Aeronautics and Astronautics, Massachusetts Institute of Technology, 77 Massachusetts Ave, Cambridge MA 02139.

${ }^{2}$ Nancy G. Leveson, Professor, Department of Aeronautics and Astronautics and Engineering Systems Division, Massachusetts Institute of Technology, Room 33-334, 77 Massachusetts Ave., Cambridge MA 02139

${ }^{3}$ We define safety broadly in this paper, as is traditional in the space and defense communities: it is not limited to human death or injury, but also includes equipment and mission losses. Risk is a broader concept than safety, as there are also risks of overrunning budgets and schedules or losing money (in a commercial environment). Risk also implies an analytical analysis while safety is a broad term to denote absence of unacceptable losses. To distinguish that we are talking about safety analysis, we use the term "safety risk" in this paper where confusion would result.
} 
The field of computer and software architecture, for example, has a rich history of architecture evaluation attempts that dates from the 1970s [2]. Techniques such as ATAM (Architecture Tradeoff Analysis Method) and ARID (Active Reviews for Intermediate Designs) are used to evaluate quality attributes (including performance, availability, security, modifiability etc...) of software architectures [3, 4]. There are many difficulties associated with the use of these evaluation techniques [5, 6]. Among others, current evaluation techniques usually require a fair amount of detail before they become effective. The earlier evaluation attempts are made, the more uncertainty in the result. While the uncertainty may be greater, it should not prevent system architects from attempting early evaluations.

Another problem is that architecture evaluation attempts often focus on the most salient properties of a system, such as cost (For example, Function Points, COnstructive COst MOdel (COCOMO) [7, 8] and others [6] in software engineering) while leaving out other properties such as system safety as a problem to be addressed later in the development lifecycle. This is a mistake because many architecture decisions have a significant and lasting impact on safety and may not be reversible after an architecture is selected. For example, the early decision not to add a crew escape system on the space shuttle was based on early architectural decisions and has been impacting shuttle safety for over 20 years $[9,10]$.

Similarly, during the development of large space systems, early trade studies focus on cost (often using mass as a proxy) and performance as the main properties to evaluate potential system architecture and design alternatives. Incorporating safety risk into the decision making at this stage is an important goal: If information about risk were available early, it could be used in the architectural selection process and hazards could be designed out of the system or mitigated early when the cost of doing so is much less than later in the system life cycle. Making basic design changes downstream becomes increasingly costly as development progresses and, often, compromises in safety must be accepted that could have been eliminated if safety had been considered earlier. The problem is that information about the likelihood of particular hazardous events is usually unknown before an architecture and a system design are selected. While it is relatively easy to identify hazards at system conception, performing a hazard analysis or risk assessment before a design is available is more problematic. 
Risk is usually treated as a combination of severity and likelihood. For safety risk, the events considered are the identified hazards. Classic Preliminary Hazard Analysis is performed using a Risk Matrix $[11,12]$ which provides a combination of these two hazard properties. Although formats can differ slightly, the general form of such a Risk Matrix is shown in Figure 1. High-level system hazards are first identified and, for each identified hazard, a qualitative risk evaluation is performed by classifying the hazard according to its severity and likelihood.

\begin{tabular}{|c|c|c|c|c|c|}
\hline & \multicolumn{4}{|c|}{ SEVERITY } \\
\hline & & $\begin{array}{c}\text { I } \\
\text { Catastrophic }\end{array}$ & $\begin{array}{c}\text { II } \\
\text { Critical }\end{array}$ & $\begin{array}{c}\text { III } \\
\text { Marginal }\end{array}$ & $\begin{array}{c}\text { IV } \\
\text { Negligible }\end{array}$ \\
\hline & A Frequent & $\mathrm{I}-\mathrm{A}$ & II-A & III-A & IV-A \\
\hline & B Moderate & I-B & II-B & III-B & IV-B \\
\hline ᄃ & C Occasional & $\mathrm{I}-\mathrm{C}$ & $\mathrm{II}-\mathrm{C}$ & III-C & IV-C \\
\hline & D Remote & I-D & II-D & III-D & IV-D \\
\hline & E Unlikely & I-E & II-E & III-E & IV-E \\
\hline & F Impossible & $\mathrm{I}-\mathrm{F}$ & II-F & III-F & IV-F \\
\hline
\end{tabular}

Figure 1: Standard Risk Matrix

While severity can usually be evaluated using the worst possible consequences of that hazard, the likelihood of the hazard before any system design is performed or even earlier when a system architecture has not yet been selected, is unknown and, arguably, unknowable in most complex space systems. Some probabilistic information is available about physical events, of course, and historical information is theoretically available. Spacecraft designs, however, often include new technology and design features that limit the accuracy of historical information. For example, historical information about the likelihood of propulsion-related losses in previous spacecraft may not be accurate for new designs using nuclear propulsion. In addition, the use of software and digital systems is introducing new ways for hazards to occur that cannot be analyzed using standard hazard analysis techniques that assume accidents 
are caused by system component failures or using statistical techniques that assume randomness. The difficulty in predicting hazard likelihood is especially great at the very beginning of conceptual studies, where virtually no design information is available. Inaccurate a priori evaluations of hazard likelihood inevitably lead to incorrect risk assessments that can compromise the safety of the system. Discounting the risk associated with potential hazards due to an overoptimistic initial evaluation of likelihood can lead to unnecessary losses.

The analysis described in this paper takes into account the randomness of some events such as micrometeroid strikes, solar flares, and some mechanical failures, but it also recognizes that complex aerospace systems often fail in nonrandom ways. For example, the root causes of the Challenger and Columbia losses included inadequate management decision-making and evaluation of the safety risk of identified and documented hazards due to political, economic, and performance pressures $[13,9,14]$.

Likelihood estimation must also account for losses resulting not from component failure but from dysfunctional interactions among components. The loss of the Mars Polar Lander, for example, has been attributed to noise generated when the landing legs were deployed during descent [15]. This noise was normal and expected and did not represent a failure in the landing leg system. The onboard software interpreted these signals as an indication that landing occurred (which the software engineers were told they would indicate) and shut the engines down prematurely, causing the spacecraft to crash into the planet surface. In this loss, and in many other recent spacecraft losses related to software [16], no component "failed"-the landing legs and the software performed correctly (i.e., as specified in their requirements), but the loss occurred due to dysfunctional interaction among these spacecraft components.

As digital components proliferate in spacecraft, this type of component interaction accident will increase. Hazard analyses that assume accidents are caused by random component failures will miss this type of accident, which is typical for systems including digital components. Classic hazard analysis techniques such as fault tree analysis and failure modes and effects analysis do not work well in these types of system interaction accidents not involving component failures and alternatives are needed [17]. This topic is beyond the scope of this paper, however, which 
focuses on the early system architecture selection process when the system design information needed for these hazard analysis techniques is not available anyway.

We know of no existing rigorous or scientific way to obtain probabilistic or even subjective likelihood information using historical data or analysis in the case of non-random failures and system design errors, including unsafe software behavior. When forced to come up with such evaluations, engineering judgment is usually used, which in most cases amounts to pulling numbers out of the air. Selection of a system architecture on such a basis is questionable and perhaps one reason why risk is usually not used in the early architectural trade process.

In this paper, we propose a new way of performing likelihood analysis as part of a standard preliminary hazard analysis that can be started at the beginning of the system lifecycle, before architecture selection, and used to inform the early architecture trade studies. Later, after an architecture is selected, the information generated in the analyses can be used to design hazards out of the system during the detailed design process as the original analyses are revised and refined. In this paper, we cover only the incorporation of risk into the architectural design selection and trade studies. Safety-driven design is described elsewhere [18, 19].

The new analysis technique uses the hazard mitigation potential of multiple candidate architectures to estimate hazard likelihood. Hazards that are more easily mitigated in the design and operations are less likely to lead to accidents, and similarly, hazards that have been eliminated during system design simply cannot lead to an accident. Thus the goal of the analysis process described in this paper is to assist in selecting an architecture with few serious hazards and inherently high mitigation potential for those hazards that cannot be eliminated, perhaps because eliminating them would reduce the potential for achieving other important system goals.

We chose mitigation potential as a surrogate for likelihood for two reasons: (1) the potential or eliminating or controlling the hazard in the design has a direct and important bearing on the likelihood of the hazard occurring (whether traditional or new designs and technology is used) and (2) mitigatibility of the hazard can be determined before an architecture or design is selected — indeed, it helps in the design selection process. 
We acknowledge up front the difficulty of providing an evaluation of our approach. Waiting until a complex space system using this approach has been built and operated for a reasonable amount of time could take decades and is impractical. A carefully controlled experiment is not feasible. Comparing the results obtained to alternatives in an informal way would be possible if there were alternatives. The only alternative we know that has been suggested is simply expert judgment, which is actually a part of our approach (but augmented and guided) and thus is not independent of it. We start with expert judgment and add information and analysis. Therefore, we are left only with an argument based on our experience in performing or reviewing dozens of preliminary hazard analyses in a variety of systems and industries. We hope that the proposal in this paper will spark more interest in coming up with alternatives that could later be compared and evaluated.

The new process is demonstrated using a MIT/Draper Labs project to perform an early concept evaluation and refinement for the NASA space exploration mission. The goal was to develop a space exploration architecture that fulfills the needs of the many stakeholders involved in the exploration enterprise. Safety was defined upfront as one of the most critical criteria for a successful space exploration enterprise. Because safety is an important property to many of the stakeholders, using it to influence early architectural decisions was important as most of these architectural decisions would be very costly or impossible to change later in the development process. Although the new hazard analysis methodology was used for the entire space exploration architecture, this paper for practical reasons includes only the transportation subset — bringing humans from earth orbit to the Moon/Mars surface and returning them back to earth orbit. Earth launch and re-entry, as well as Moon/Mars surface operations are omitted but can be found in the NASA final reports. Note that we use this project only as an example of the new safety risk assessment procedure and do not evaluate their overall technology and approach to architecture generation in this paper.

The next section briefly describes important elements of the space exploration example used throughout the paper. In the rest of the paper, the methodology is described and sample results presented. 


\section{The Space Exploration Example}

The new US Space Exploration Vision involves a return to the moon as a stepping-stone for the future human exploration of Mars. During the concept evaluation and refinement performed jointly by MIT and Draper Labs, 1162 possible Earth-to-Moon/Mars-and-Back transportation architectures were generated. The architectures were generated by selecting transportation vehicles and functions based on a set of combination rules and constraints (see [20] for a description of the object-based architecture generation framework used). Although the risk analysis procedure described in this paper could have been used up-front as one of the initial architecture filtering criteria, it was decided to initially filter out highly inefficient architectures from a mass and feasibility perspective and then perform a risk evaluation on the remaining architectures. Because of the large number of architectures considered in the architectural generation approach used, this choice seems reasonable but the risk analysis approach proposed in this paper applies either way.

In this context, an architecture can be defined as the combination of a transportation architecture with a list of parameters and options related to technology utilization, policy and operations. ${ }^{4}$ A transportation architecture includes:

1) The number and type of vehicles and modules used to send humans and cargo to the Moon/Mars surface and return them to Earth

2) The role and activities for each vehicle/module, including:
a. Dockings and un-dockings
b. Trajectories and orbit insertions
c. Assembly of vehicle/modules stacks
d. Discarding of vehicles/modules
e. Prepositioning of vehicles/modules in orbit and on the planet surface

\footnotetext{
${ }^{4}$ The completeness and appropriateness of the specific options considered in the MIT/Draper Labs project is not relevant to the safety risk analysis approach being demonstrated in this paper; any selection of parameters and options would still work.
} 
A sample transportation architecture is shown in Figure 2. In this simple architecture, a single flight (Flight 2) is used to transport crew and cargo from the Earth (E) to the Moon (M) surface and back. Flight 1 includes a Crew Exploration Vehicle (CEVa) a Trans Moon-Mars Injection module, surface descent (DSc) and ascent modules (AS), and a Trans-Earth Injection (TEI) Module for the return. Modules on the right of Figure 2 are discarded at various stages of the mission. For example, the Surface descent module (DSc) is left on the Moon's surface.

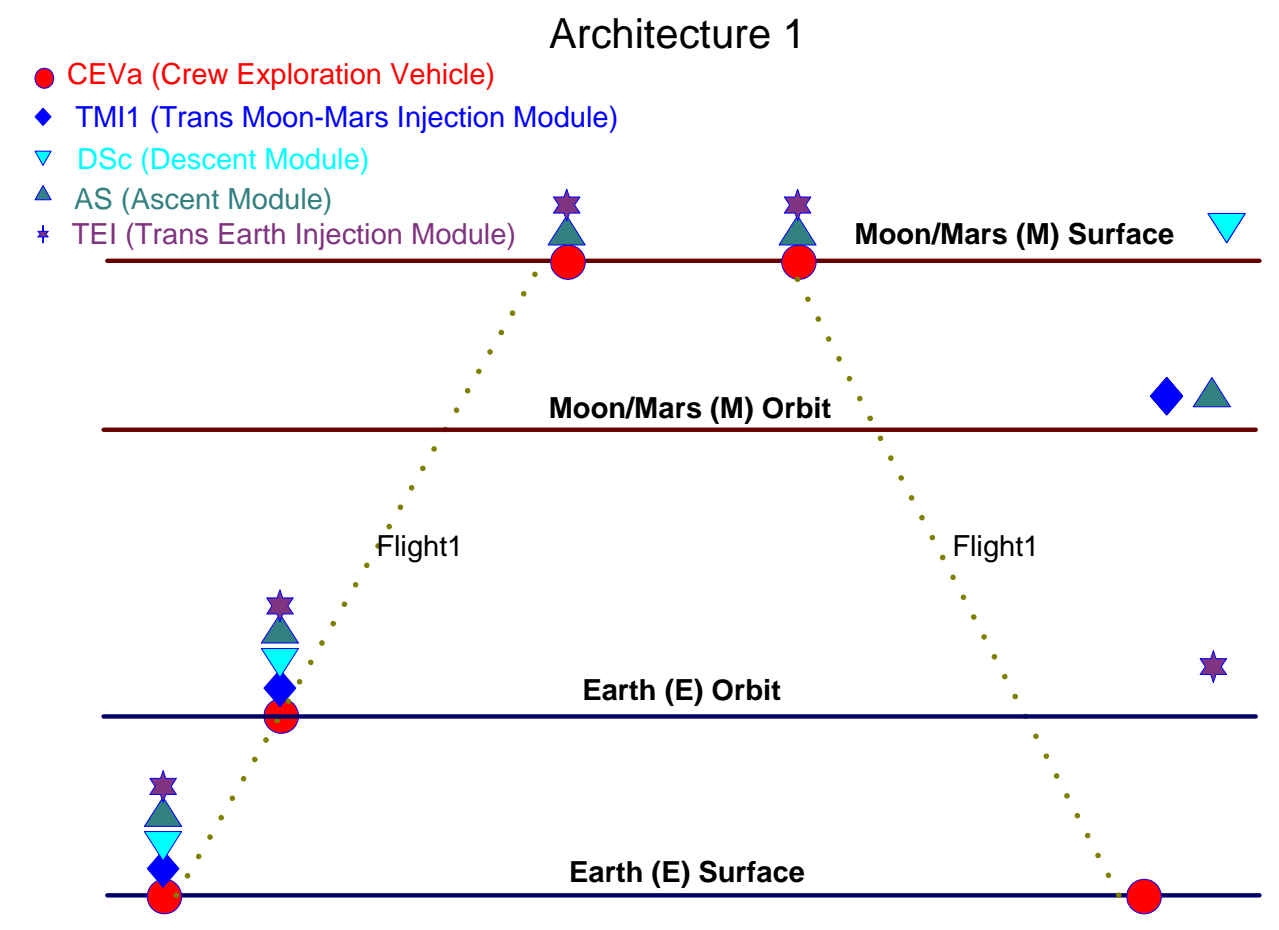

Figure 2: Sample One-Flight Transportation Architecture

Figure 3 shows a more complex architecture where two outbound flights are required. Flight 4 is used to preposition cargo and assets such as a surface habitat (HAB4b), an ascent propulsion module (AS), and a return Crew Exploration Vehicle (CEVb) to the $\mathrm{M}$ surface. Once asset prepositioning is complete, Flight 1 brings the crew to the surface using an outbound Crew Exploration Vehicle (CEVa) and Transfer Habitat (HAB1).

In addition to a transportation architecture, a complete exploration architecture includes a set of parameters related to areas such as technology, propulsion, policy, and operations. Tables 1, 2, and 3 provide a list of some parameters and options used in the architecture definition and associated safety analysis. The total architectural space can be 
theoretically obtained by taking the cross product of all the available architectural options, including the transportation architecture and additional options.

\section{Architecture 881}

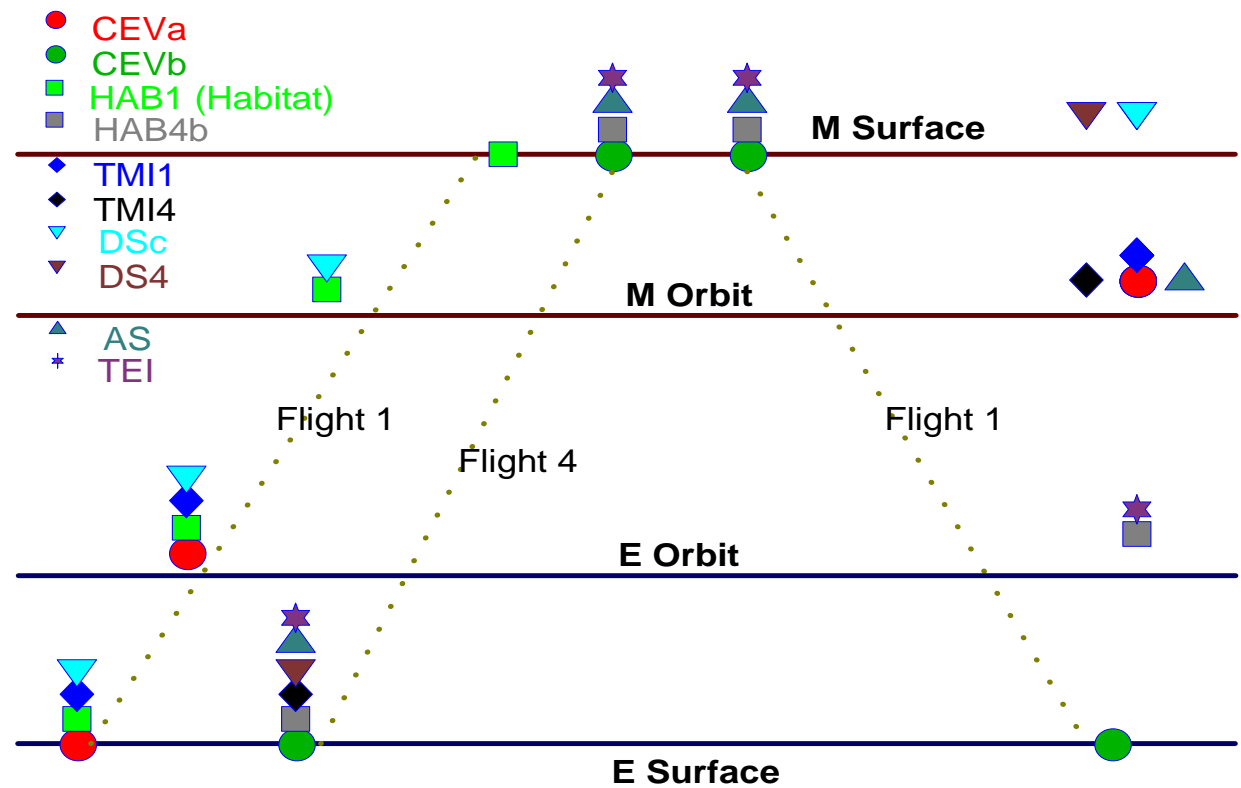

Figure 3: Sample Two-Flights Transportation Architecture 
Table 1: Technology Options used in the Exploration Architecture Definition

\begin{tabular}{|l|c|c|}
\hline Technology Options: & Option 1 & Option 2 \\
\hline ISRU (In-Situ Resource Utilization) & NO & YES \\
\hline Aerocapture & NO & YES \\
\hline Nuclear Thermal Rockets & NO & YES \\
\hline Solar Electric Propulsion (for Cargo) & NO & YES \\
\hline Nuclear Electric Propulsion & NO & YES \\
\hline Nuclear Surface Power & NO & YES \\
\hline Level of Autonomy & LOW & HIGH \\
\hline Highly Elliptical Orbital Rendezvous & NO & YES \\
\hline Rendezvous in transit & NO & YES \\
\hline Artificial gravity & NO & YES \\
\hline High-Closure Environmental Control and Life & & NO \\
\hline Support System (ECLSS) (water, oxygen) & NO & YES \\
\hline Low boil-off propellant storage & NO & YES \\
\hline In-space propellant transfer & & \\
\hline
\end{tabular}

Table 2: Propulsion Options used in the Exploration Architecture Definition

\begin{tabular}{|l|c|c|c|c|c|}
\hline Propulsion Options: & Option 1 & Option 2 & Option 3 & Option 4 & Option 5 \\
\hline & & Methane & & & \\
Transfer to M & Hydrogen (H2) / Liquid & $(\mathrm{CH} 4) /$ & & \\
& Oxygen (LOX) & LOX & Hypergolic & Nuclear & Electric \\
\hline Arrival to M & $\mathrm{H} 2 / \mathrm{LOX}$ & $\mathrm{CH} 4 /$ LOX & Hypergolic & Nuclear & \\
\hline Descent and Ascent & $\mathrm{H} 2 /$ LOX & CH4 / LOX & Hypergolic & Nuclear & \\
\hline Return to Earth & $\mathrm{H} 2 /$ LOX & CH4 / LOX & Hypergolic & Nuclear & Electric \\
\hline
\end{tabular}


Table 3: Policy and Operational Options used in the Exploration Architecture Definition

\begin{tabular}{|c|c|c|c|}
\hline Policy / Operational Options: & Option 1 & Option 2 & Option 3 \\
\hline Heavy Lift Launch Vehicle (HLLV) & $\mathrm{NO}$ & YES & \\
\hline Crew size & 0 & 1 & $2+$ \\
\hline Habitable Modules during TMI & - & 1 & $2+$ \\
\hline Habitable Modules on Surface & - & 1 & $2+$ \\
\hline Human/Cargo Transfer & SEPARATE & COUPLED & \\
\hline Nuclear & NO & YES & \\
\hline De-investing in the moon & NO & YES & \\
\hline Level of international involvement & LOW & HIGH & \\
\hline Level of commercial involvement & LOW & HIGH & \\
\hline Free-return trajectory & $\mathrm{NO}$ & YES & \\
\hline Initial Mars mission duration & SHORT & LONG & \\
\hline Level of abort options & LOW & MEDIUM & HIGH \\
\hline Mars landing sites & SINGLE & MULTI & CHAIN \\
\hline Surface elements reusability & $\mathrm{NO}$ & YES & \\
\hline Transportation elements reusability & $\mathrm{NO}$ & YES & \\
\hline
\end{tabular}

\section{Hazard-Based Safety Risk Analysis Methodology}

The hazard-based safety risk analysis developed is a three-step process:

1. Identify the system-level hazards and associated severities

2. Identify mitigation strategies and associated impact

3. Calculate safety/risk metrics for a given transportation architecture

The first two steps are performed only once, at the beginning of the process. They may have to be repeated if the architectural design space changes or if additional hazards are identified. The third step is repeated in order to evaluate as many transportation architectures and variations as necessary. The following sections discuss each of the three steps in more detail. 


\section{Step 1: Identify System-Level Hazards and Severities}

Just as in typical hazard analyses, the first step in the methodology is to identify the system-level hazards. A Hazard Identification Worksheet (HIW) can be used to streamline this process and to ensure proper tracking of the hazards.

Figure 4 shows the worksheet used for the space exploration example. This worksheet includes the standard information usually included in a hazard log during a preliminary hazard analysis [21] but it augments it with the mitigation-related information needed for the new analysis approach.

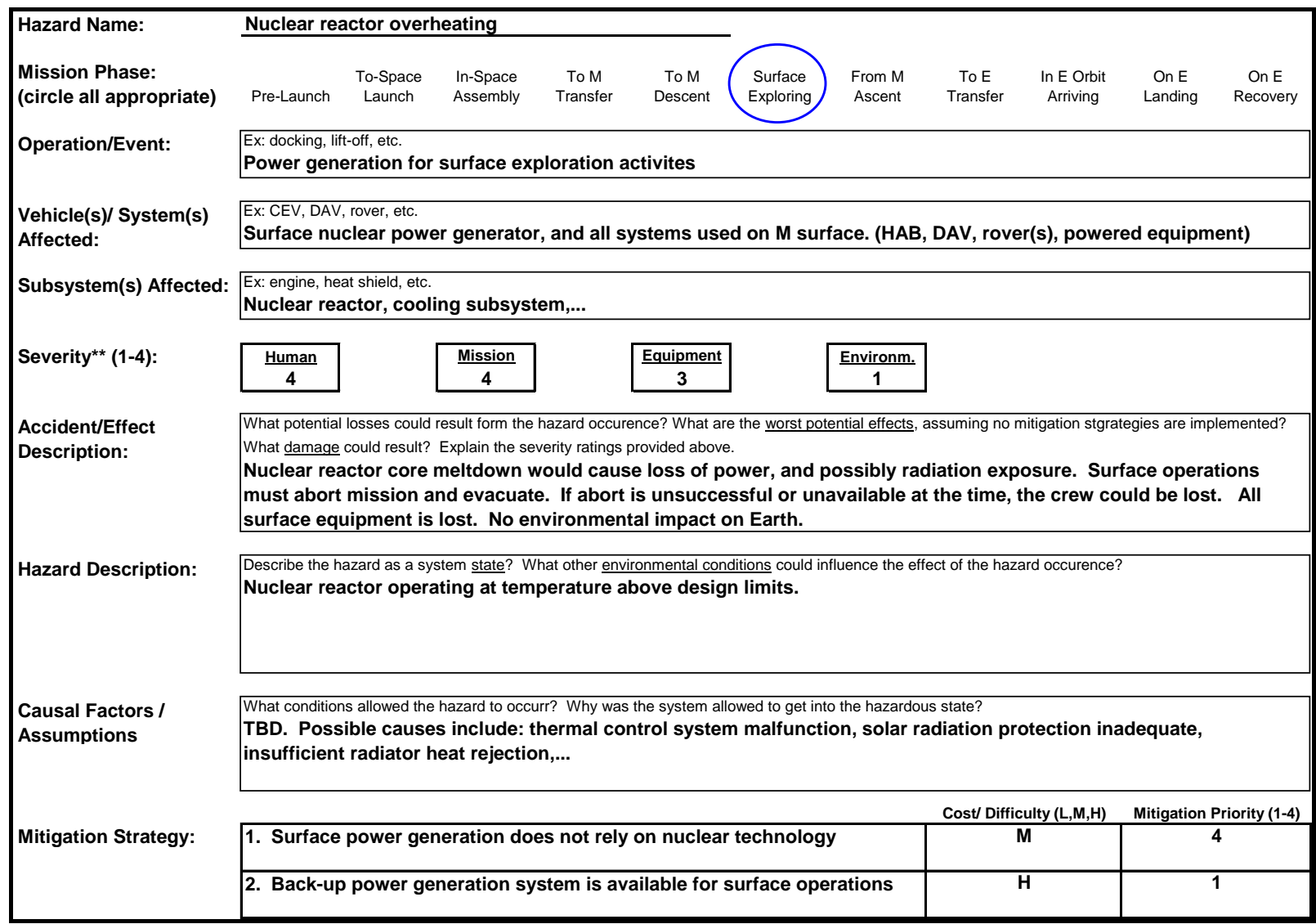

\section{Figure 4: Hazard Identification Worksheet}

As with any preliminary hazard analysis activities, identifying system-level hazards involves $10 \%$ creativity and $90 \%$ experience. Consequently, domain experts should be closely involved in identifying hazards for each mission phase. 
Once the hazards are identified, the severity of each hazard is evaluated by considering the worst-case loss associated with the hazard. In the example, the losses were evaluated for each of three categories: Humans (H), Mission (M), and Equipment (E). Initially, potential damage to the earth and planet surface environment was included in the hazard log. In the end, the environment component was left out of the analysis because project managers decided to replace it with mandatory compliance with NASA's planetary protection standards. A more comprehensive analysis should include the inherent potential of a system to mitigate environmental hazards. The methodology presented in this article can be easily extended to do so. A custom severity scale (see Table 4) was defined to account for the losses associated with each category. Some hazards identified, such as fire, explosion, or loss of life-support span multiple (if not all) mission phases. These hazards were grouped under the label "general" hazards to simplify the analysis. However, the mitigation strategies associated with these hazards depend on the mission phase to which they apply.

Table 4: Custom Hazard Severity Scale

\begin{tabular}{|c|c|c|c|}
\hline \multirow{2}{*}{$\begin{array}{c}\text { Severity } \\
\text { Level }\end{array}$} & Human & Mission & Equipment \\
\cline { 2 - 4 } & Loss of Life & Mission abort or mission loss & System Loss \\
\hline $\mathbf{4}$ & Severe injury or illness & Major mission objectives incomplete & Major System Damage \\
\hline $\mathbf{3}$ & Minor injury or illness & Minor mission objectives incomplete & Minor System Damage \\
\hline $\mathbf{2}$ & Less than minor injury or illness & All mission objectives completed & Less than minor System Damage \\
\hline $\mathbf{1}$ & &
\end{tabular}

Table 5 shows a summary of the identified hazards and severities, organized by mission phase. Again, we relied on the judgment of the experts involved in the project to assess severity as is common practice in preliminary hazard analysis. Assessment of severity is not usually difficult or controversial. 
Table 5: System-Level Hazards and Associated Severities

\begin{tabular}{|c|c|c|c|c|c|}
\hline \multirow[b]{2}{*}{$\mathrm{DH}$} & \multirow[b]{2}{*}{ Phase } & \multirow[b]{2}{*}{ Hazard } & \multicolumn{3}{|c|}{ Severity } \\
\hline & & & H & M & Eq \\
\hline G2 & General & Flamable substance in presence of ignition source in confined space (Explosion) & 4 & 4 & 4 \\
\hline G5 & General & Solar or nuclear radiation exceeding safe levels & 3 & 3 & 2 \\
\hline G6 & General & Collision (Morometeroids, debris, with modules during rendevous or separation maneuver, etc.) & 4 & 4 & 4 \\
\hline G7 & General & Loss of attitude control & 4 & 4 & 4 \\
\hline$P L 2$ & Pre-Launch & Launch delav (due to weather, pre-launch test failures, etc.) & 1 & 4 & 1 \\
\hline LI & Launch & Incorrect propusionitrajectory/control during ascent & 4 & 4 & 4 \\
\hline 2 & Launch & Loss of structural integrity (due to aerodynamic loads, vibrations, etc) & 4 & 4 & 4 \\
\hline L3 & Launch & Incorrect stage separation & 4 & 4 & 4 \\
\hline E1 & EVA in Space & Lost in space & 4 & 4 & 1 \\
\hline$\overline{A 1}$ & Assembly & Incorrect propulsion/control during rendevous & 4 & 4 & 4 \\
\hline$A_{2}$ & Assembly & Inability to dock & 1 & 4 & 3 \\
\hline $\mathrm{D} 3$ & Descent & Loss of structural integrity (due to inadequate themmal control, aerodynamic loads, vibrations, etc) & 4 & 4 & 4 \\
\hline A1 & Ascent & Incorrect stage separdion (including ascent module disconnecting from descent stage) & 4 & 3 & 3 \\
\hline A2 & Ascent & Incorrect propulsiondtrajectoryicontrol during ascent & 4 & 3 & 3 \\
\hline A3 & Ascent & Loss of structural integrity (due to aerodynamic loads, vibrations, etc) & 4 & 3 & 3 \\
\hline$\$ 1$ & Surface Operations & Crew members stranded on M surface during EVA & 4 & 3 & 3 \\
\hline$\$ 2$ & Surface Operations & Crew members lost on M surface during EvA & 4 & 3 & 3 \\
\hline$\$ 3$ & Surface Operations & Equipment damage (including related to lunar dust) & 2 & 3 & 3 \\
\hline NP1 & Nuclear Power & Nuclear fuel released on earth surface & 4 & 4 & 2 \\
\hline $\mathrm{NP}_{2}$ & Nuclear Power & Insufficient power generation (reactor doesn't work) & 4 & 3 & 3 \\
\hline NP3 & Nuclear Power & Insufficient reactor cooling (leading to reactor meltdown) & 4 & 3 & 3 \\
\hline RE1 & Re-Entry & Inability to undock & 4 & 3 & 3 \\
\hline RE2 & Re-Entry & Incorrect propulsionitrajectorvicontrol during descent & 4 & 3 & 3 \\
\hline $\mathrm{RE} 3$ & Re-Entry & Loss of structural integrity (due to inadequate themmal control, aerodvnamic loads, vibrations, etc) & 4 & 3 & 4 \\
\hline RE4 & Re-Entry & Inclement weather & 4 & 2 & 2 \\
\hline
\end{tabular}

\section{Step 2: Identify Mitigation Strategies and Associated Impact}

The second step of the methodology involves the identification and assessment of possible mitigation strategies for each hazard. The architectural space has a tendency to change very rapidly at the beginning of a project when different options are being explored at a fast pace. Fortunately, the methodology is highly flexible and allows for rapid re-evaluations of architectures when changes occur. The key to this analysis is to determine the impact of each architectural option on each system-level hazard. In order to do so, a four level hazard mitigation impact scale is used (Table 6). This scale is based on typical system safety hazard mitigation priority scales [21] and is used to determine the impact (if any) of a given architecture option on a given hazard.

In the space exploration example, a database of mitigation impact was generated with the help of domain experts and was recorded in a spreadsheet. It contains the mitigation impact (1-4) of each architectural option, for each hazard, for each category (Human, Mission, Equipment). 
Table 6: Hazard mitigation Scale and Priority

\section{Mitigation Impact}

\begin{tabular}{|c|c|c|}
\hline Level & General Description & Detailed Description \\
\hline 4 & Eliminate & Complete elimination of the hazard from the design \\
\hline 3 & Prevent & Reduction of the likelihood that the hazard will occur \\
\hline 2 & Control & Reduction of the likelihood that the hazard results in an accident \\
\hline 1 & Reduce Damage & Reduction of damage to the system if an accident does occur \\
\hline
\end{tabular}

Table 7 shows only a small part of the database created to record hazard mitigation information and evaluate architectures. The system-level hazards and their associated severities (human, mission, and equipment) are listed in the top rows. The architectural and technology options are listed in the column on the left. The architectural space is divided into parameters with alternatives, for example, the parameter of launch vehicle type includes a binary alternative for the use of a Heavy Launch Vehicle (HLLV). Many of the available architectural options are hidden to make the table more readable (e.g. chemical propellant options).

The effects of architectural parameters and technology options on each hazard are recorded in the database according to the 1-4 mitigation scale. For example, not performing Rendezvous in Transit and/or Highly Elliptical Orbital Rendezvous reduces the likelihood of a collision between modules and vehicles (Mitigation Level 3). Similarly, the use of an unmanned architecture (Crew size $=0$ ) completely removes the potential for human loss (Mitigation Level 4), but does not directly impact potential mission or equipment losses. As in any hazard analysis process, documenting the rationale and assumptions for each hazard, mitigation strategy and impact is critical. For complex system architectures, the mitigation database can be very large, which makes it impossible for analysts to remember the inputs of every domain expert. Consequently, database updates and changes can be very difficult unless the mitigation strategies and impact were carefully documented and linked to source material. Once the hazard mitigation database has been populated, it is possible to start evaluating the overall mitigation potential of various exploration architectures. 
Table 7: Sample Hazard Mitigation Database

\begin{tabular}{|c|c|c|c|c|c|c|c|c|c|c|c|c|c|c|c|c|c|c|c|c|c|c|c|c|c|}
\hline \multirow[b]{3}{*}{ Design/Architecture Parameter } & \multirow[b]{3}{*}{1} & \multirow{2}{*}{\multicolumn{3}{|c|}{$\begin{array}{l}\text { G1 } \\
\text { Fire }\end{array}$}} & \multirow{2}{*}{\multicolumn{3}{|c|}{\begin{tabular}{c|} 
G2 \\
Explosion
\end{tabular}}} & \multirow{2}{*}{\multicolumn{3}{|c|}{\begin{tabular}{|c|} 
G3 \\
$\begin{array}{c}\text { Loss of Life } \\
\text { Support }\end{array}$ \\
\end{tabular}}} & \multirow{2}{*}{\multicolumn{3}{|c|}{\begin{tabular}{|c|} 
G4 \\
$\begin{array}{c}\text { Crew Injury } \\
\text { or IIIness }\end{array}$
\end{tabular}}} & \multirow{2}{*}{\multicolumn{3}{|c|}{$\begin{array}{c}\text { G5 } \\
\text { Collision }\end{array}$}} & \multirow{2}{*}{\multicolumn{3}{|c|}{$\begin{array}{c}\text { G6 } \\
\text { Loss of } \\
\text { Structural } \\
\text { Integrity }\end{array}$}} & \multirow{2}{*}{\multicolumn{3}{|c|}{$\begin{array}{c}\text { G8 } \\
\text { Loss of } \\
\text { Attitude } \\
\text { Control }\end{array}$}} & \multirow{2}{*}{\multicolumn{3}{|c|}{\begin{tabular}{|c|} 
G9 \\
Incorrect \\
Propulsion \\
/ Control
\end{tabular}}} \\
\hline & & & & & & & & & & & & & & & & & & & & & & & & & \\
\hline & & 4 & 4 & 4 & 4 & 4 & 4 & 4 & 4 & 4 & 4 & 3 & 1 & 4 & 4 & 4 & 4 & 4 & 4 & 4 & 4 & 4 & 4 & 4 & 4 \\
\hline $\begin{array}{c}\text { ISRU - Yes } \\
\text { ISRU - No }\end{array}$ & 1 & 1 & 1 & 1 & 1 & 1 & 1 & 2 & $\begin{array}{l}2 \\
3\end{array}$ & & & & & & & & & & & & & & & & \\
\hline $\begin{array}{l}\text { Aerocapture - Yes } \\
\text { Aerocapture - No }\end{array}$ & 1 & 1 & 1 & 1 & 1 & 1 & 1 & & & & & & & & & & 3 & 3 & & & & & & & \\
\hline $\begin{array}{l}\text { Nuclear Thermal Rockets - Yes } \\
\text { Nuclear Thermal Rockets - No }\end{array}$ & 1 & 1 & 1 & 1 & 1 & 1 & 1 & & & & & & & & & & & & & & & & & & \\
\hline $\begin{array}{l}\text { Solar Electric Propulsion - Yes } \\
\text { Solar Electric Propulsion - No }\end{array}$ & 1 & 1 & 1 & 1 & 1 & 1 & & & & & & & & & & & & & & & & & & 3 & 3 \\
\hline $\begin{array}{l}\text { Nuclear Electric Propulsion - Yes } \\
\text { Nuclear Electric Propulsion - No }\end{array}$ & 1 & 1 & 1 & & 1 & 1 & & & & & & & & & & & & & & & & & & 3 & 3 \\
\hline $\begin{array}{l}\text { Rendevous in transit - Yes } \\
\text { Rendevous in transit - No }\end{array}$ & 1 & & & & & & & & & & & & & & 3 & 3 & & & & 3 & 3 & 3 & 3 & 3 & 3 \\
\hline $\begin{array}{l}\text { Artificial gravity - Yes } \\
\text { Artificial gravity - No }\end{array}$ & 1 & & & & & & & & & & 3 & & & & & & & & & & & & & & \\
\hline $\begin{array}{l}\text { High-closure ECLSS }(\mathrm{H} 2 \mathrm{O}, \mathrm{O} 2) \text { - Yes } \\
\text { High-closure ECLSS }(\mathrm{H} 2 \mathrm{O}, \mathrm{O} 2) \text { - No }\end{array}$ & 1 & & & & & & & 3 & 3 & & & & & & & & & & & & & & & & \\
\hline $\begin{array}{l}\text { In-space propellant transfer - Yes } \\
\text { In-space propellant transfer - No }\end{array}$ & 1 & 3 & 3 & 3 & 3 & 3 & 3 & & & & & & & & & & & & & & & & & & \\
\hline $\begin{array}{c}\text { HLLV - Yes } \\
\text { HLLV - No }\end{array}$ & 1 & & & & & & & & & & & & & & & & & 3 & & & & & & & \\
\hline $\begin{array}{l}\text { Nuclear - Yes } \\
\text { Nuclear - No }\end{array}$ & 1 & & & & & & & & & & & & & & & & & & & & & & & & \\
\hline $\begin{array}{l}\text { Free-return trajectory - Yes } \\
\text { Free-return trajectory - No }\end{array}$ & 1 & 3 & & & 3 & & & 3 & & & 3 & & & & & & & & & & & & 2 & & \\
\hline $\begin{array}{l}\text { Initial Mars mission duration - Long } \\
\text { Initial Mars mission duration - Short }\end{array}$ & 1 & & & & & & & 2 & 2 & & 2 & & & & & & & & & & & & & & \\
\hline $\begin{array}{l}\text { Level of abort options - High } \\
\text { Level of abort options - Moderate } \\
\text { Level of abort options - Low }\end{array}$ & 1 & & & & & & & 3 & 3 & & 1 & 1 & & & & & & & & & & & & & \\
\hline $\begin{array}{l}\text { Crew size }-0 \\
\text { Crew size }-1+\end{array}$ & 1 & 4 & & & 4 & & & 4 & & & 4 & & & 4 & & & 4 & & & 4 & & & 4 & & \\
\hline
\end{tabular}

\section{Step 3: Evaluate Architectures and Calculate Safety/Risk Metrics}

As previously mentioned, a complete exploration architecture is defined as the union of the transportation architectures with a set of technology/policy parameter options. In order to evaluate the risk associated with a specific architecture, an architecture vector is created that includes all of the parameters for that architecture. This vector is in the form of a large string of binary numbers. A sample architecture vector can be found in the second column of Table 7. The " 1 " values in the vector indicate that the corresponding option is selected. In this example, the vector shows that the selected architecture includes:

1. In-Situ Resource Utilization (ISRU)

2. Aerocapture

3. No Nuclear Thermal Rockets 
4. No Solar Electric Propulsion

5. No Nuclear Electric Propulsion

6. No Rendezvous in Transit

7. Etc.

An architecture vector has to be created for each architecture evaluation. The architecture vector generation process can easily be automated if a large number of evaluations have to be performed. Once an architecture vector has been defined, the risk evaluation and metrics computation proceeds as follows:

1. For each hazard and each hazard category (human, mission, equipment), that is, for each column of the spreadsheet, the algorithm scans for the option that provides the maximum hazard mitigation for each architectural parameter. These Maximum Mitigation Factors are added to obtain the sum-total maximum hazard mitigation factor for each hazard and each category (H,M,E). The Maximum Mitigation Factors and their sum-total are architecture-independent. They only depend on the architectural option space and the hazard mitigations identified. The process of searching for maximum mitigation factors should be automated to provide the flexibility necessary to modify the architectural space and to make the tool evolvable. The maximum mitigation factors obtained in this step are almost never achievable in real-life because of potential impracticality or cost or because that would require unacceptable tradeoffs with other system requirements and constraints such as mass, performance or development schedule. For example, selecting an unmanned mission (Crew Size $=0$ ) reduces human risk considerably, but it conflicts directly with the essence of the Space Exploration Vision. Nevertheless, the maximum hazard mitigation factor is important because it provides an architecture-independent theoretical absolute upon which all the other architectures can be compared.

2. To evaluate a specific architecture, the algorithm matches the selected options with their respective hazard mitigation impact and computes a sum of the mitigation factors obtained for the options selected in the architecture under evaluation. This process is repeated for each hazard and category (H, M, E). The result is a set of Hazard Mitigation Indices obtained for a particular architecture. 
3. A Relative_Residual_Risk_Index is calculated for each hazard (h) and each category (c) using the following formula:

Relative_Residual_Risk_Index $(h, c)=(1-$

$($ Hazard_Mitigation_Index(h,c)/Maximum_Mitigation_Factor $(h, c)))$

4. If a hazard and/or category is completely eliminated (Mitigation_Level=4) by a selected architectural option, the Relative_Residual_Risk_Index for this hazard is automatically set at zero.

5. A post-mitigation Relative_Severity_Index for each hazard and category is then calculated as follows:

Relative_Severity_Index $(\mathrm{h}, \mathrm{c})=($ Relative_Residual_Risk_Index $(h, c)) *$ Original_Hazard_Severity $(h)^{2} . \quad$ The "squared" severity is used to provide heavier weighting on the higher severity indices (see the weighting factors used in the MIT/Draper project. Weighting factors are system-dependent and have to be discussed with analysts and project managers because they have a significant impact on the final analysis results. Relative severity rating is always subjective and a decision that is usually made at the project management or organizational level. We chose a weighting factor that seemed appropriate for this particular project and was acceptable to the engineers participating, but other weightings are possible and easily implemented.

6. Three Relative_Risk_Metrics (Human, Mission, Equipment) are obtained by averaging the Relative_Severity_Indices for each category $(\mathrm{H}, \mathrm{M}, \mathrm{E})$ across all hazards.

7. As needed, an Overall Residual Safety-Risk Metric (ORSRM) for an architecture can be obtained using a weighted average of the Relative Severity Indices for each category (H, M, E) with custom weighted factors $(\mathrm{H}, \mathrm{M}, \mathrm{E})$ selected by the project team. In this project, the weighting factors selected were: Human: 9, Mission: 3, Equipment: 1. Again, different weighting factors can be used, depending on the judgment and goals of the particular project or organization. 
Table 8: Weighting Factors used in Calculating ORSRM

\begin{tabular}{|c|c|c|c|c|}
\cline { 3 - 5 } \multicolumn{1}{c|}{} & & Human & Mission & Equipment \\
\hline Hazard Severity & Weight & 9 & 3 & 1 \\
\hline 4.Catastrophic & 16 & & & \\
\hline 3.Critical & 9 & & & \\
\hline 2.Major & 4 & & & \\
\hline 1.Marginal & 1 & & & \\
\hline
\end{tabular}

The hazard mitigation metrics are used to evaluate and rank potential transportation architectures. By systematically selecting and deselecting options in the architecture description, it is possible to perform a first-order assessment of the relative importance of each architectural option in determining the Overall Residual Safety-Risk Metric (ORRRM).

\section{Sample Results}

The results from the analysis provide a ranking of the selected transportation architectures based on the hazard mitigation potential of each. Hundreds of parameters are considered in the Safety/Risk analysis, but the analysis allowed the identification of major contributors to the hazard mitigation potential of selected architectures. These contributors include the use of heavy module and equipment pre-positioning on the surface of mars and the use of minimal rendezvous and docking maneuvers. Pre-positioning modules allows for pre-testing and mitigates the hazards associated with loss of life support, equipment damage, and so on. On the other hand, pre-positioning modules increases the reliance on precision landing to ensure that all landed modules are within range of each other. Consequently, using heavy pre-positioning may require additional mitigation strategies and technology development to reduce the risk associated with landing in the wrong location. As another example, a transportation architecture requiring no docking at Mars orbit or upon return to Earth inherently mitigates hazards associated with collisions or failed rendezvous and docking maneuvers. On the other hand, having the capability to dock during an emergency, even though it is not required during nominal operation, provides additional mitigation to loss of life support, especially in Earth orbit.

Hundreds of architectures were evaluated for their inherent hazard mitigation potential. After multiple down selections, three very different Mars Baseline Architectures (MB1, MB2, MB3) were selected as final candidates 
(see Figure 5). In this analysis, MB1 was evaluated with the use of in-situ resource utilization (ISRU) because a direct return from the Martian surface is not possible using the MB1 transportation architecture unless propellant is extracted from local resources. MB3 was evaluated with Nuclear Thermal Rockets propulsion, which shortens the transit time but requires additional mitigation for hazards associated with the use of nuclear power (radiation, contamination, overheating, inadequate propulsion/control, high structural loads, etc.).

An automated tool was created to perform multiple evaluations based on the needs of the team responsible for designing the transportation architecture. As mentioned previously, hundreds of different architecture evaluations have been performed with little maintenance and data input efforts. The analysis started at the very beginning of the conceptual design phase and the methodology proved flexible and extensible enough to carry the team from Day 1 of conceptual design up to the beginning of the detailed design phase, at which point, a more detailed hazard analysis methodology such as STPA [17, 18] will be necessary and safety-driven design of the system and its components can be started [18, 19].

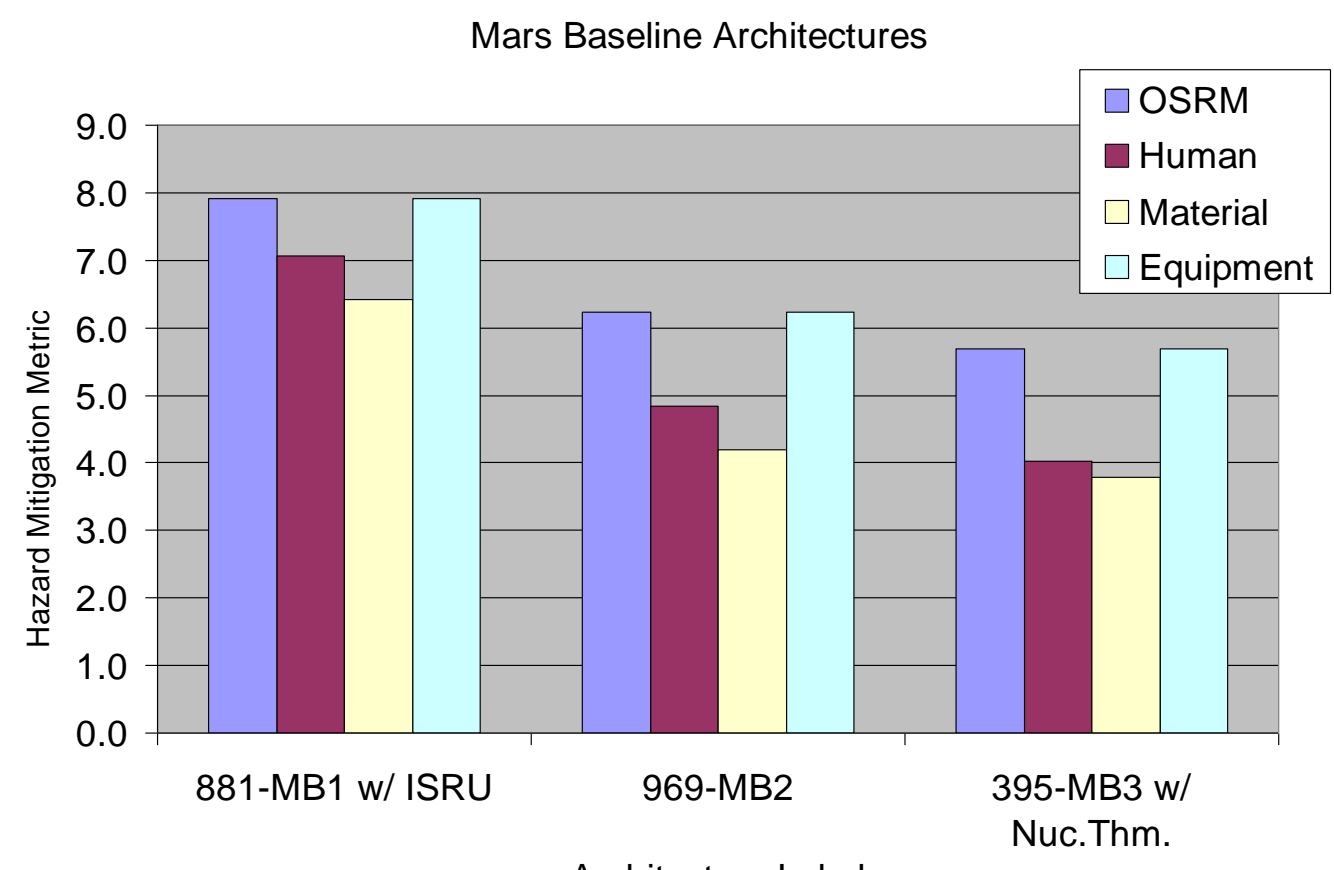

Architecture Label 


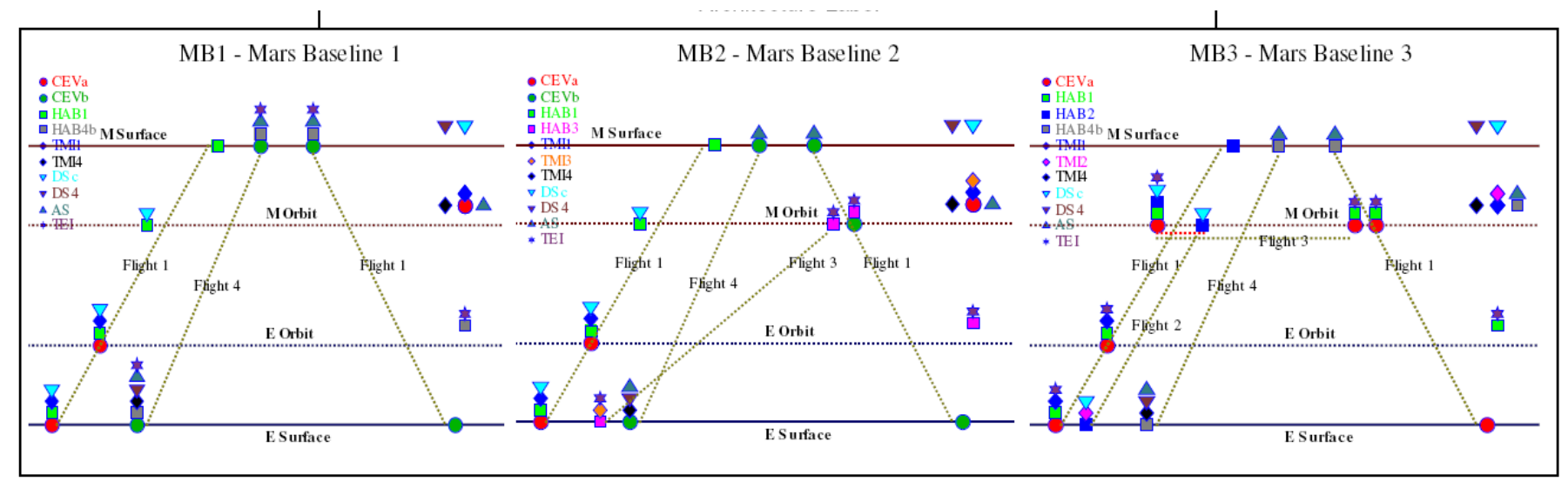

Figure 5: Evaluation Results for three Mars Baseline Architectures

\section{Conclusions}

The methodology described in this paper was developed to assist in performing structured preliminary hazard analysis during early system architecture trade studies. Such a methodology allows considering the inherent hazard mitigation potential of candidate system architectures early in system development when safety can be increased relatively cheaply without the need for costly downstream development changes or compromises. As shown in the example, the methodology handles highly complex, broad-scoped, multi-vehicle, time-dependent systems and is flexible, extensible, and adaptable to other types of complex systems.

The example in the paper focused on describing the methodology using a very structured transportation architecture generation scheme. However, the methodology was applied with equal success to perform a structured preliminary hazard analysis of the surface operations mission architecture of the same project. The information available for the surface architecture evaluation had very different format, content, and context, but the hazard mitigation analysis was similar. The application of the methodology in the early system architecture trade studies for this project demonstrated that a highly structured preliminary hazard analysis process using mitigation potential as an estimator of likelihood in a safety risk evaluation is feasible and practical in a project of this size and complexity. 
As discussed in the introduction, the accuracy of the results cannot be directly evaluated and rests on the assumption that being able to mitigate hazards affects the likelihood of their occurrence. There is no way to scientifically prove this assumption at this time, but it seems a reasonable assumption for spacecraft designers to make and, indeed, underlies all attempts to increase safety through engineering design.

\section{Acknowledgements}

This work was partially supported by a NASA CE\&R contract to MIT and Draper Labs and by a grant (NAG21543) from the NASA Engineering for Complex Systems Program. We would like to thank all the Draper Labs engineers and MIT faculty and students who contributed to the risk analysis described in this paper.

\section{References}

1. Blanchard B.S. and Fabrycky, W.J., Systems Engineering and Analysis, 3rd ed., Prentice-Hall, Englewood Cliffs, New Jersey, 1998.

2. White J.R. and Booth, T.L., "Towards an Engineering Approach to Software Design," Proceedings of the Second International Conference on Software Engineering (ICSE), IEEE Computer Society, San Francisco, 1976, pp. 214-222.

3. Barbacci M., Carriere, J., Kazman, R., Klein, M., Lipson, H., Longstaff, T., and Weinstock, C., Steps in an Architecture Tradeoff Analysis Method: Quality Attribute Models and Analysis, Technical Report CMU/SEI-97-TR-029, Software Engineering Institute, CMU, May 1998.

4. Clements, P., Kazman, R. and Klein, M., Evaluating Software Architectures: Methods and Case Studies, Addison-Wesley Publishers, Boston, MA, 2002.

5. Chatman, V.V., "Change points: A proposal for software productivity measurement," Journal of Systems and Software, Vol. 31, No. 1, 1995, pp. 71-91.

6. Kemerer, C.F., "An Empirical Validation of Software Cost Estimation Model,". Communications of the ACM, Vol. 30, No. 5, Association for Computing Machinery, 1987, pp. 416-429.

7. Boehm B.W., Software Engineering Economics, Prentice Hall PTR: Englewood Cliffs, NJ, 1981. 
8. Boehm B.W., Abts, C., Brown, A.W., Chulani, S., Clark, B.K, Horowitz, E., Madachy, R., Reifer, D.J., and Steece, B., Software Cost Estimation with COCOMO II. Prentice Hall PTR, Englewood Cliffs, NJ, 2000.

9. Gehman, H. (Chair), Columbia Accident Investigation Report, National Aeronautics and Space Administration, Washington, D.C., 2003.

10. McCurdy, H., Inside NASA: High Technology and Organizational Change in the U.S. Space Program, Johns Hopkins University Press, 1994.

11. NASA General Safety Program Requirements, NPR 8715.3C, NASA, March 2008

12. Standard Practice for System Safety, MIL-STD-882D, Department of Defense, 10 February, 2000.

13. Rogers, W.R. (Chair), Report of the Presidential Commission on the Space Shuttle Challenger Accident, U.S. Government Accounting Office, Washington D.C., 1986.

14. Leveson, N.G. "Technical and Managerial Factors in the NASA Challenger and Columbia Losses: Looking Forward to the Future," in Handelsman and Fleishman (eds.), Controversies in Science and Technology, Vol. 2: From Chromosomes to the Cosmos, Mary Ann Liebert, Inc., 2007, pp. 237-261.

15. JPL Special Review Board, Report on the Loss of the Mars Polar Lander and Deep Space 2 Missions, NASA Jet Propulsion Laboratory, 22 March 2000

16. Leveson, N.G., "The Role of Software in Spacecraft Accidents," Journal of Spacecraft and Rockets, Vol. 41, No. 4, July-August 2004, pp. 564-575

17. Leveson N.G., System Safety Engineering: Back to the Future, MIT Press, Cambridge, MA, 2009, in press (draft available at http://sunnyday.mit.edu/book2.pdf).

18. Owens, B., Herring, M., Leveson, N.G., Ingham, M., Weiss, K.A., "Application of a Safety-Driven Design Methodology to an Outer Planet Exploration Mission," in IEEE Aerospace Conference, Big Sky, Montana, March 2008, pp. 174-193.

19. Leveson N.G. and Dulac, N., "Safety and Risk Driven Design in Complex Systems of Systems," NASA/AIAA First NASA Space Exploration Conference, Orlando Florida, 2005: Orlando, FL, pp. 57-74.

20. Koo, H.B., A Meta-Language for System Architecting, Ph.D. Dissertation, Engineering Systems Division, Massachusetts Institute of Technology, Cambridge, MA, 2005.

21. Leveson N.G., Safeware: System Safety and Computers, Addison-Wesley, Reading, MA, 1995. 